\title{
The relationship between carbon dioxide sensitivity and sprint or endurance performance in young swimmers
}

\author{
S. P. McGurk MEd, B. A. Blanksby PhD and M. J. Anderson MEd \\ Department of Human Movement, University of Western Australia, Nedlands WA 6009, Australia
}

\begin{abstract}
There has been some evidence that extremes of $\mathrm{CO}_{2}$ sensitivity can indicate an individual's potential for sprint or endurance athletic performance. This study examined the responses to $\mathrm{CO}_{2}$ rebreathing, and previously validated sprint and endurance tests by subjects who were involved in regular, but not intensive, swimming training. The aim was to determine whether subjects with low $\mathrm{CO}_{2}$ sensitivity might perform better on endurance tests, whilst those subjects with high $\mathrm{CO}_{2}$ sensitivity would be more successful in the sprint tests.

Initially, 168 young $(\bar{X}$ mean(s.d.) age $=12.4(2.1)$ years) swimmers were measured using a modified version of the Read $^{1} \mathrm{CO}_{2}$ rebreathing technique. From this sample, 17 high $\left(\bar{X}\right.$ mean(s.d.) $\left.=2.24(0.39) 1 \mathrm{~min}^{-1} \mathrm{mmHg}^{-1}\right) \mathrm{CO}_{2}$ responders were matched by gender, age, height, weight and FVC with 17 low $\left(\bar{X}\right.$ mean(s.d.) $=0.57(0.19) 1$ min $^{-1}$ $\mathrm{mmHg}^{-1}$ ) responders. Each of these 17 pairs underwent two sprint tests (10 s Tri-level alactic power, $50 \mathrm{~m}$ run) and two endurance tests $\left(\mathrm{PWC}_{170}, 1.6 \mathrm{~km}\right.$ run) in order to determine whether any differences existed between the two groups and the sprint and endurance parameters. The subjects remained unaware of their results of the rebreathing test throughout testing. A dependent $t$ test was then used to compare the results collected from each group.

The low $\mathrm{CO}_{2}$ responders recorded a significantly faster $1.6 \mathrm{~km}$ run time, but were not superior on the $P W C_{170}$ ergometer test, than the high $\mathrm{CO}_{2}$ responders. The high $\mathrm{CO}_{2}$ responding group recorded significantly higher results on the $10 \mathrm{~s}$ alactic power test, but not the $50 \mathrm{~m}$ sprint run, than the low responders. Hence, further study is required to ascertain underlying causes as to why significant differences occurred with $\mathrm{CO}_{2}$ rebreathing, the $1.6 \mathrm{~km}$ run and the $10 \mathrm{~s}$ alactic power test, but not with the $\mathrm{PWC}_{170}$ and the $50 \mathrm{~m}$ sprint run.
\end{abstract}

Keywords: $\mathrm{CO}_{2}$ rebreathing, talent identification, young swimmers, sprint/endurance performance

As it takes many years of regular training to excel in most sports, athletes need to take up the activity well before the age at which it is generally expected that their best performances occur. Early recognition of any attribute which would benefit an athlete in developing through these formative years would assist in choosing those events to which an individual is best suited.

Address for correspondence: Associate Professor B. A. Blanksby
Some research has demonstrated that athletes in general tend to possess a reduced sensitivity to $\mathrm{CO}_{2}^{2-7}$, while others have found no significant difference between athletes and non-athletes ${ }^{8-12}$. Others have noted significant differences between endurance (aerobic) athletes who have exhibited a low ventilatory response and sprint (anaerobic) athletes who have possessed a high response ${ }^{13,14}$. Another study found no changes occurred after a 5 month training period ${ }^{15}$.

The association between athleticism and ventilatory response to $\mathrm{CO}_{2}$ is not well understood. Perhaps a decreased ventilatory response may produce dyspnoea and thus an enhanced exercise tolerance ${ }^{16}$. Furthermore, if low respiratory drives give a functional advantage during aerobic exercise then an increase in respiratory drive may decrease exercise performance over time. Such persons may be best suited to the shorter, anaerobic events where a higher ventilatory rate is needed. If blunted chemosensitivity to $\mathrm{CO}_{2}$ is evident in successful endurance athletes it would be valuable to determine whether this attribute is an acquired or an inherited trait.

To examine whether the chemical drive to ventilation is controlled by genetic factors, 20 pairs of young monozygotic twins $(\bar{X}$ age $=16.4 \mathrm{yr})$ and 11 pairs of dizygotic twins were used in an age, body size and gender ratio matched study ${ }^{17}$. Results indicated that, in adolescent twins, sensitivity to hypercapnia involved genetically determined factors. It was postulated that these results may be explained by the large numbers of twins examined or by the fact that their relative youth made their $\mathrm{CO}_{2}$ responses less susceptible to the influence of environmental factors ${ }^{18}$.

Other studies have attempted to ascertain the role of the environment in altering an individual's $\mathrm{CO}_{2}$ hypercapnia response. The results have been inconclusive because some have concluded that environmental influence is strong $12,19,20$; some have found both genetic and environmental factors are important $t^{17,21}$; and others have considered that the genetic role is predominant ${ }^{13,15,16,22}$.

This study examined whether there was any significant relationship between the sprint and endurance capabilities of a group of young people who have either a high or low ventilatory response to $\mathrm{CO}_{2}$ and who were not heavily trained. 


\section{Subjects and methods}

One hundred and eighty healthy school children aged between 8 and 15 years volunteered as subjects for the study (118 males; 62 females). Each subject was involved in a swimming programme in the Department of Human Movement at the University of Western Australia. The subjects were involved in regular swimming training, attending two or three training sessions each week of $1-1 \frac{1}{2} h$ duration for each session, but were not heavily trained.

The subjects fasted for at least $2 \mathrm{~h}$ before the appointment and avoided analgesics, caffeine and intensive exercise prior to the test. Female subjects who had undergone menarche were tested during the midfollicular phase of the cycle in an attempt to minimize the variations in ventilatory drive that had been attributed to the cyclical hormonal fluctuation of progesterone ${ }^{6,23,24}$.

Height, weight and forced vital capacity were recorded. The ventilatory response to $\mathrm{CO}_{2}$ was then assessed using the rebreathing method first established by Read ${ }^{1}$ and later modified by Rebuck ${ }^{25}$. This involved rebreathing a hyperoxic mixture of $93 \%$ oxygen and $7 \% \mathrm{CO}_{2}$ for a period of between 3 and $4 \mathrm{~min}$. During this time both ventilation $\left(\mathrm{V}_{\mathrm{e}}\right)$ and end tidal $\mathrm{CO}_{2}$ were continuously monitored and recorded.

The linearity of the subsequent increase of end tidal $\mathrm{PCO}_{2}$ and $\mathrm{V}_{\mathrm{e}}$ with time, allowed a direct plot of $\mathrm{V}_{\mathrm{e}}$ against end tidal $\mathrm{CO}_{2}$. A regression line was fitted by the least squares method and the parameters of the regression equation used to define the response. Male and female groups were then separated and a matched pairs design was undertaken in order to compare high and low responders.

A low $\mathrm{CO}_{2}$ sensitivity (S) score from one subject was paired with a high score from another subject of the same sex. In order to objectively enforce a selection criterion, a minimum of two standard deviations between the $\mathrm{CO}_{2}$ sensitivity scores of each matched pair was maintained. This was to ensure that sufficient differentiation occurred with each couple on the rebreathing status. Furthermore, on the parameters of age, height, weight and forced vital capacity, only scores of less than one standard deviation were accepted as being analogous.

From the total of 168 subjects, 17 pairs were able to be matched as above. These included 12 pairs of males and five pairs of females, and represented $20 \%$ of the total sample. Physical performance testing was carried out via a $50 \mathrm{~m}$ dash, alactic peak power test, $1.6 \mathrm{~km}$ run and a $P W C_{170}$. The investigators involved with the performance testing were unaware of the $\mathrm{CO}_{2}$ sensitivity status of each subject.

\section{Statistics}

The hypercapnic ventilatory drive was analysed by a least squares regression using the equation:

$\mathrm{V}_{\mathrm{e}}=\mathrm{S}\left(\mathrm{P}_{\mathrm{a}} \mathrm{CO}_{2} \mathrm{~B}\right)$

where $\mathrm{V}_{\mathrm{e}}=$ minute ventilation; $\mathrm{P}_{\mathrm{a}} \mathrm{CO}_{2}=$ alveolar $\mathrm{CO}_{2}$ partial pressure; $\mathrm{S}=$ the slope of the line derived from plotting $\mathrm{V}_{e}$ against $\mathrm{P}_{\mathrm{a}} \mathrm{CO}_{2}$. It is a measure of the ventilatory responsiveness per unit change in $\mathrm{P}_{\mathrm{a}} \mathrm{CO}_{2}$ $\left(\mathrm{V}_{\mathrm{e}} / \mathrm{P}_{\mathrm{a}} \mathrm{CO}_{2}\right) ; \mathrm{B}=$ extrapolated intercept on the $\mathrm{P}_{\mathrm{a}} \mathrm{CO}_{2}$ axis and represents an imaginary threshold of the $\mathrm{CO}_{2}$ sensory system.

Measures of $\mathrm{V}_{\mathrm{e}}$ and $\mathrm{P}_{\mathrm{a}} \mathrm{CO}_{2}$ were obtained from the raw data and at least six points were used from each graph for analysis. Only a goodness of fit correlation greater than 0.90 was accepted.

Physical performance parameters were then measured in an attempt to determine the sprint and endurance ability between each of the 17 matched pairs. A dependent $t$ test was adopted to establish whether any statistical difference existed between the sprint and endurance capabilities of each group.

\section{Results}

A summary of the means and the standard deviations from the 17 pairs of high and low responding subjects, including their physical parameters and physical performance results, are provided in Table 1. The endurance capabilities of subjects who revealed a low sensitivity to $\mathrm{CO}_{2}$, performed significantly better on the previously validated $1.6 \mathrm{~km}$ run when compared to those subjects with a high $\mathrm{CO}_{2}$ response $(P<0.05)$. These subjects also recorded better than average $1.6 \mathrm{~km}$ run times when compared to Australian norms of children of the same age and gender ${ }^{26}$. Sprinting capabilities of the young swimmers with a high sensitivity to $\mathrm{CO}_{2}$ performed significantly better on the $10 \mathrm{sec}$ alactic test when compared to those subjects with a low $\mathrm{CO}_{2}$ response $(P<0.05)$. No significant difference was evident from the high responding $\mathrm{CO}_{2}$ sensitivity group when compared to the Australian norms for the $50 \mathrm{~m}$ run times.

However, no significant differences existed between $\mathrm{CO}_{2}$ sensitivity of low and high responding groups when compared to the results of the $\mathrm{PWC}_{170}$ bicycle ergometer test and $50 \mathrm{~m}$ run.

When the paired $\mathrm{S}$ responders were compared to

Table 1. Mean physical characteristics, ventilatory chemosensitivity and physical performance test results of paired low and high responding subjects

\begin{tabular}{|c|c|c|}
\hline Variable & $\begin{array}{l}\text { Low responses } \\
\quad(\mathbf{n}=17)\end{array}$ & $\begin{array}{l}\text { High responders } \\
\quad(\mathrm{n}=17)\end{array}$ \\
\hline Male & 12 & 12 \\
\hline Female & 5 & 5 \\
\hline \multicolumn{3}{|l|}{ Hypercapnic response } \\
\hline $\mathrm{S} 1 \mathrm{~min}^{-1} \mathrm{mmHg}$ & $0.57(0.19)$ & $2.24(0.39)$ \\
\hline $\mathrm{B} \mathrm{mmHg}$ & 43.36(7.39) & $51.78(3.63)$ \\
\hline Average age (yrs, mths) & $12.30(2.00)$ & $12.80(2.10)$ \\
\hline Height $(\mathrm{cm})$ & $152.70(12.10)$ & $155.10(13.20)$ \\
\hline Weight (kg) & $43.60(11.60)$ & $45.30(8.80)$ \\
\hline Forced vital capacity (1) & $2.96(1.01)$ & $3.05(0.80)$ \\
\hline \multicolumn{3}{|l|}{ Endurance tests } \\
\hline $1.6 \mathrm{~km}$ run $(\min , \mathrm{s})$ & $6: 59.0 *(0: 52.0)$ & $7.45(1: 10.0)$ \\
\hline $\mathrm{PWC}_{170}\left(\mathrm{kgm} \mathrm{kg}^{-1} \mathrm{~min}^{-1}\right)$ & $15.52^{\mathrm{NS}}(3.43)$ & $15.11(3.57)$ \\
\hline \multicolumn{3}{|l|}{ Sprint tests } \\
\hline $50 \mathrm{~m}$ run (s) & $8.52^{\mathrm{NS}}(0.75)$ & $\begin{array}{r}8.40(0.80) \\
11.91(2.79)\end{array}$ \\
\hline $10 \mathrm{~s}$ alactic power $(\mathrm{w} / \mathrm{kg})$ & $11.02 *(2.20)$ & $11.91(2.79)$ \\
\hline
\end{tabular}

All values are mean(s.d.); ventilatory response to $\mathrm{CO}_{2}$ was analysed by the equation $\mathrm{V}=\mathrm{S}\left(\mathrm{P}_{\mathrm{a}} \mathrm{CO}_{2}-\mathrm{B}\right) ;{ }^{*}$ significance between high and low responders $(P<0.05)$; ns Not significant 
the Australian norms for the $50 \mathrm{~m}$ and $1.6 \mathrm{~km}$ runs, there was no evidence to suggest that individuals with a low $\mathrm{CO}_{2}$ sensitivity had reduced sprint capabilities. Conversely, those individuals with a high $\mathrm{CO}_{2}$ sensitivity showed no signs of having reduced endurance capabilities.

\section{Discussion}

The 17 low $S$ responders recorded significantly $(P<0.05)$ faster $1.6 \mathrm{~km}(6 \mathrm{~min} 59 \mathrm{~s})$ run times than their physically matched counterparts $(7 \mathrm{~min} 45 \mathrm{~s}$ ). Thus, the findings agreed with previous research which specifically examined endurance runners and revealed a significantly lower $S$ response when results were compared to non-athletes, or athletes of a non-endurance nature $2,4,6,13,27$. However, no significant difference was detected between the paired subjects undertaking the $\mathrm{PWC}_{170}$ bicycle ergometer test. It was expected that the low $S$ group would register a significantly increased score $\left(\mathrm{kgmkg}^{-1}\right.$ $\mathrm{min}^{-1}$ ) but, although they recorded a slightly higher mean response, it was not significantly different from that of the high responders. The $\mathrm{PWC}_{170}$ is considered a valid test for determining the cardiorespiratory endurance of children aged between 8 and 14 years ${ }^{28}$ but there is a chance of $a \pm 15 \%$ error factor ${ }^{29}$. Otherwise there is no obvious explanation as to why the $1.6 \mathrm{~km}$ run and $\mathrm{PWC}_{170}$ were not more compatible.

No previous study has discriminated each test group on extreme $S$ values rather than on athletic performance. Previous research studies have examined proven endurance capabilities of their subjects which were already established. In this study the subjects were relatively untrained and the minimal training they had done was similar for all 168 subjects. What was determined before performance testing was that the $S$ values for each pair were different ( $>2 \mathrm{~s}$.d.); while their physical parameters of gender, age, height, weight and vital capacity were more closely matched ( $<1$ s.d.). The high responders tended to be slightly older and, consequently, tended to be taller, heavier and had larger lung capacities (Table 1).

This enabled the performance of each paired subject to be measured without having any prior knowledge of his/her endurance sprint capabilities.

It was hypothesized that the 17 high responders would run faster than the 17 low responders in a $50 \mathrm{~m}$ sprint run and perform better on the $10 \mathrm{~s}$ alactic power test. Although this occurred in both activities, it was only in the $10 \mathrm{~s}$ alactic power test that a significant difference was revealed between the two groups $(P<0.05)$ (See Tables 1 and 2$)$.

Other studies have revealed that a high level of $\mathrm{CO}_{2}$ sensitivity is linked to sprint performance and lower than normal $\mathrm{CO}_{2}$ sensitivity levels have been observed in exceptional sprint performers when compared to a non-athletic population ${ }^{14}$. However, when these $S$ values were compared to endurance performers involved in the same study, the values of the sprinters were somewhat higher. One difficulty is that non-athletic populations can frequently reveal superior physical characteristics which are genetically based but have never been tested because they have never tried athletic participation. They could be potential Olympians were they to participate.

If there is a functional advantage from having a low respiratory drive to exercise, then any individuals who have an increased respiratory drive may have limited endurance performance. Reports indicate that subjects with a higher sensitivity to $\mathrm{CO}_{2}$ had a higher resting respiratory frequency. Under prolonged stressful exercise this may inhibit endurance capabilities $^{30}$.

There is evidence in the present study to suggest that a high ventilatory response to $\mathrm{CO}_{2}$ may be a prerequisite to successful sprint performance as indicated by the significant relationship with the $10 \mathrm{~s}$ alactic power test $(P<0.05)$. However, no significance was found between a high $\mathrm{S}$ score and the $50 \mathrm{~m}$ run, and no explanation can be found for such a discrepancy. It is confusing that one bicycle test $(10 \mathrm{~s}$ alactic power - sprint) was significant but not the other ( $\mathrm{PWC}_{170}$ - endurance). Also, one run $(1.6 \mathrm{~km}-$ endurance) was significant but not the other $(50 \mathrm{~m}-$ sprint). Again, no conclusive reason can be offered for this.

The Australian Health and Fitness Survey ${ }^{26}$ provided an opportunity to compare physical performance results of the sprint and endurance runs of our subjects to norms provided for other boys and girls of the same sex and age. Tables 3 and 4 summarize these results after raw scores have been converted to percentile rankings. Even though the subjects were in the early stages of a swimming season and had no long-term background of training, they would probably have some fitness advantage over average youngsters included in a national survey. However, it does provide a yardstick for substantiating, or otherwise, subjects' performances.

Table 2. Dependent $t$ test results from the 17 matched pairs of high and low $\mathrm{CO}_{2}$ sensitivity (S) and results from the physical performance tests

\begin{tabular}{|c|c|c|c|c|c|c|}
\hline Variable & $\mathbf{N}$ & Mean difference & $S d e v$ & t value & p value & Significance $(\mathrm{P}<0.05)$ \\
\hline \multicolumn{7}{|l|}{ Endurance tests } \\
\hline $1.6 \mathrm{~km}$ run & 17 & 0.76 & 1.16 & 2.70 & 0.01 & significant \\
\hline PWC $_{170}$ & 17 & -0.46 & 1.82 & -1.03 & 0.32 & n.s. \\
\hline \multicolumn{7}{|l|}{ Sprint tests } \\
\hline $50 \mathrm{~m}$ run & 17 & -0.19 & 0.71 & -1.09 & 0.29 & n.s. \\
\hline $10 \mathrm{~s}$ alactic power & 17 & 0.89 & 1.69 & 2.17 & 0.04 & significant \\
\hline
\end{tabular}

n.s. Not significant 
After each paired individual was compared with percentile ranks, some trends were evident. Whilst there were minimal differences in the percentile rankings for the $50 \mathrm{~m}$ running times between the two groups, the low responders performed significantly better in the $1.6 \mathrm{~km}$ run and demonstrated less variation as determined by the standard deviations of their performance.

Table 3. Percentile ranks of height, weight, $50 \mathrm{~m}$ and $1.6 \mathrm{~km}$ run times of the 17 low $\mathrm{S}$ responders when compared to Australian Health and Fitness Survey norms for children of the same age and sex

\begin{tabular}{rcccccc}
\hline Pair no. & Sscores & Sex & Height & Weight & $\begin{array}{c}1.6 \mathrm{~km} \\
\text { run }\end{array}$ & $\begin{array}{c}50 \mathrm{~m} \\
\text { run }\end{array}$ \\
\hline 1 & & & & & & \\
2 & 0.55 & $\mathrm{M}$ & 65 & 75 & 95 & 30 \\
3 & 0.36 & $\mathrm{M}$ & 45 & 40 & 95 & 75 \\
4 & 0.46 & $\mathrm{~F}$ & 55 & 35 & 95 & 35 \\
5 & 0.47 & $\mathrm{~F}$ & 65 & 55 & 85 & 80 \\
6 & 0.60 & $\mathrm{M}$ & 80 & 70 & 85 & 50 \\
7 & 0.44 & $\mathrm{M}$ & 5 & 15 & 95 & 50 \\
8 & 0.27 & $\mathrm{M}$ & 65 & 60 & 95 & 40 \\
9 & 0.76 & $\mathrm{M}$ & 95 & 85 & 45 & 75 \\
10 & 0.64 & $\mathrm{M}$ & 30 & 45 & 95 & 80 \\
11 & 0.21 & $\mathrm{M}$ & 50 & 40 & 75 & 15 \\
12 & 0.61 & $\mathrm{~F}$ & 95 & 65 & 95 & 90 \\
13 & 0.85 & $\mathrm{M}$ & 80 & 75 & 95 & 60 \\
14 & 0.60 & $\mathrm{M}$ & 5 & 25 & 95 & 55 \\
15 & 0.69 & $\mathrm{~F}$ & 70 & 55 & 60 & 30 \\
16 & 0.73 & $\mathrm{M}$ & 80 & 90 & 40 & 75 \\
17 & 0.89 & $\mathrm{~F}$ & 40 & 20 & 90 & 95 \\
Mean(s.d.) & $0.57(0.19)$ & & $57(27)$ & $54(23)$ & $84(18)$ & $61(25)$ \\
\hline
\end{tabular}

Percentiles taken every $5 \%$. Closest achieved percentile recorded. Lowest $=5 \%$ ile. Highest $=95 \%$ ile. $S=1 \mathrm{~min}^{-1}$ $\mathrm{mmHg}^{-1}$

Table 4. Percentile ranks of height, weight, $50 \mathrm{~m}$ and $1.6 \mathrm{~km}$ run times of the 17 high $\mathrm{S}$ responders when compared to Australian Health and Fitness Survey norms for children of the same age and sex

\begin{tabular}{lcccccc}
\hline Pair no. & S scores & Sex & Height & Weight & $\begin{array}{c}1.6 \mathrm{~km} \\
\text { run }\end{array}$ & $\begin{array}{c}50 \mathrm{~m} \\
\text { run }\end{array}$ \\
\hline 1 & & & & & & \\
2 & 1.80 & $M$ & 65 & 75 & 65 & 40 \\
3 & 2.11 & $\mathrm{M}$ & 25 & 20 & 85 & 90 \\
4 & 2.44 & $\mathrm{~F}$ & 85 & 85 & 90 & 95 \\
5 & 2.00 & $\mathrm{~F}$ & 70 & 90 & 20 & 25 \\
6 & 1.87 & $\mathrm{M}$ & 85 & 85 & 45 & 50 \\
7 & 1.87 & $\mathrm{M}$ & 5 & 30 & 60 & 10 \\
8 & 1.82 & $\mathrm{M}$ & 80 & 70 & 35 & 65 \\
9 & 1.94 & $\mathrm{M}$ & 80 & 50 & 95 & 40 \\
10 & 2.26 & $\mathrm{M}$ & 85 & 75 & 75 & 50 \\
11 & 2.57 & $\mathrm{M}$ & 40 & 30 & 85 & 75 \\
12 & 2.42 & $\mathrm{~F}$ & 45 & 50 & 90 & 90 \\
13 & 3.00 & $\mathrm{M}$ & 40 & 40 & 85 & 70 \\
14 & 2.46 & $\mathrm{M}$ & 45 & 50 & 55 & 60 \\
15 & 2.55 & $\mathrm{~F}$ & 90 & 50 & 60 & 75 \\
16 & 2.92 & $\mathrm{M}$ & 95 & 65 & 80 & 75 \\
17 & 2.39 & $\mathrm{~F}$ & 10 & 40 & 85 & 70 \\
Mean(s.d.) & $2.24(0.39)$ & & $59(28)$ & $56(21)$ & $67(23)$ & $63(25)$ \\
\hline
\end{tabular}

Percentiles taken every $5 \%$. Closest achieved percentile recorded. Lowest $=5 \%$ ile; Highest $=95 \%$ ile. $S=1 \mathrm{~min}^{-1}$ $\mathrm{mmHg}^{-1}$
Additionally, 13 of the 17 low responders had $1.6 \mathrm{~km}$ run times which ranked them in the top $15 \%$ for their particular sex and age group. These subjects could have been individuals with above average athletic ability.

It is difficult to ascertain the extent of this influence, yet it is unlikely to fully account for the significant difference between the $1.6 \mathrm{~km}$ run times of the low responders when compared against the Australian norms. Comparisons between the high and low responding groups with the $10 \mathrm{~s}$ alactic power test, and the $\mathrm{PWC}_{170}$, were not possible as the Australian Fitness Survey did not provide norms for these tests.

However, a high standard of performance was evident with the mean of the low responders in the $1.6 \mathrm{~km}$ run being at the 85th percentile. Furthermore, if the two low percentiles are excluded (subject $8=$ 45th percentile and subject $15=40$ th percentile), then the mean(s.d.) percentile rank for the low $S$ responders increases to $90(10.1)$. Hence, there was a strong relationship between those with a low $\mathrm{S}$ to $\mathrm{CO}_{2}$ and performance on the $1.6 \mathrm{~km}$ run, when these subjects were compared to the general population of the same sex and age. It is suggested that the low ventilatory response to $\mathrm{CO}_{2}$ is related to this enhanced performance.

On the basis of the $50 \mathrm{~m}$ run times, no such role could be associated with high ventilatory response to $\mathrm{CO}_{2}$. Although the high $\mathrm{S}$ responders in this study ran slightly faster than children of the same age and sex in the national norms (61st percentile), their times were not differentiated as being significantly faster on the $50 \mathrm{~m}$ dash when compared to those recorded by the low $\mathrm{S}$ responders.

This study sought to prospectively examine relationships between $\mathrm{CO}_{2}$ rebreathing responses and sprint/endurance performance. The results demonstrated a significant relationship between low $\mathrm{CO}_{2}$ response and endurance via the $1.6 \mathrm{~km}$ run; and a high $\mathrm{CO}_{2}$ response and sprinting via the $10 \mathrm{~s}$ alactic power test. However, the results are inconclusive because no significance was found for the $\mathrm{PWC}_{170}$ and endurance; or the $50 \mathrm{~m}$ run and sprint performance. Further study is required to elucidate the matter further.

\section{References}

1 Read DJC. A clinical method for assessing the ventilatory response to carbon dioxide. Australasian Ann Med 1967; 16: 20-32.

2 Byrne-Quinn E, Weil JV, Sodal IE, Filley GF, Grover RF. Ventilatory control in the athlete. I Appl Physiol 1971; 30: 91-8.

3 Saunders NA, Leeder SR, Rebuck AS. Ventilatory reponse to carbon dioxide in young athletes: a family study. Am Rev Respir Dis 1976; 113: 497-502.

4 Miyamura M, Yamashina T, Honda $Y$. Ventilatory responses to $\mathrm{CO}_{2}$ rebreathing at rest and during exercise in untrained subjects and athletes. Jpn J Physiol 1976; 26: 245-54.

5 Martin BJ, Sparks KE, Zwillich CW, Weil JV. Low exercise ventilation in endurance athletes. Med Sci Sports 1979; 11: 181-5.

6 Schoene RB, Robertson HT, Pierson DJ, Peterson AP. Respiratory drives and exercise in menstrual cycles of athletic and non-athletic women. I Appl Physiol 1981; 50: 1300-5.

7 Schoene RB. Control of ventilation in climbers to extreme altitude. J Appl Physiol 1982; 53(4): 886-90. 
8 Godfrey S, Edwards RH, Copland GM, Gross PL. Chemosensitivity in normal subjects, athletes, and patients with chronic airways obstruction. J Appl Physiol 1971; 30: 193-9.

9 Martin BJ, Weil JV, Sparks KE, McCullough RE, Grover RF. Exercise ventilation correlates positively with ventilatory chemoresponsiveness. J Appl Physiol 1978; 45: 557-64.

10 Mahler DA, Moritz ED, Loke J. Ventilatory responses at rest and during exercise in marathon runners. J Appl Physiol 1982; 52: 388-92.

11 Masuda Y, Yoshida A, Hayashi F, Sasaki K, Honda Y. The ventilatory responses to hypoxia and hypercapnia in the ama. Jpn J Physiol 1981; 31: 187-97.

12 Kelley MA, Laufe MD, Millman RP, Peterson DP. Ventilatory response to hypercapnia before and after athletic training. Respir Physiol 1984; 55: 393-400.

13 Rebuck AS, Read J. Patterns of ventilatory response to carbon dioxide during recovery from severe asthma. Clinical Science 1971; 41: 13-21.

14 Ohkuwa T, Fuisuka N, Utuno T, Miyamura M. Ventilatory response to hypercapnia in sprint and long-distance swimmers. Eur J Appl Physiol 1980; 43: 235-41.

15 Blanksby $\mathrm{BA}$, Morton $\mathrm{AR}$. $\mathrm{Co}_{2}$ rebreathing sensitivity in swimming. Aust J Sci Med Sport 1989; 21: 3-5.

16 Scoggin $\mathrm{CH}$, Doekel RD, Kryger MH, Weil J, Zwillich CW. Family aspects of decreased hypoxic drive in endurance athletes. J Appl Physiol 1978; 44: 464-8.

17 Kawakami Y, Yoshikawa T, Shida A, Asanuma Y, Murao M. Control of breathing in young twins. J Appl Physiol 1982; 53: $537-42$.

18 Fleetham JA, Arnup ME, Anthonisen NR. Familial aspects of ventilatory control in patients with chronic obstructive pulmonary disease. Am Rev Respir Dis 1984; 129: 3-7.

19 Kanarek DJ, Kelly DH, Shannon DC. Ventilatory chemoreceptor response in parents of children at risk for sudden infant death syndrome. Pediatr Res 1981; 15: 1402-5.
20 Arkinstall WW, Nirmel K, Klissouras V, Milic-Emili J. Genetic differences in the ventilatory response to inhaled $\mathrm{CO}_{2} . J \mathrm{Appl}$ Physiol 1974; 36(1): 6-11.

21 Blum J, Kanarek D, Callahan B, Braslow N, Kazemi H. The effect of training on $\mathrm{CO}_{2}$ ventilatory reponsiveness in normal subjects. Am Rev Respir Dis 1979; 119(Suppl): 291.

22 Miyamura M, Okuwa T, Matsui J. Ventilatory reponses to hypercapnia in swimmers and twins. Sem Blood Gases Respir Circ Chiba, 1979.

23 Damas-Mora J, Davies L, Taylor W, Jenner FA. Menstrual respiratory changes and symptoms. Br I Psychiat 1980; 136: 492-7.

24 Dutton $\mathrm{K}$, Blanksby BA, Morton AR. $\mathrm{CO}_{2}$ sensitivity changes during the menstrual cycle. J Appl Physiol 1989; 67(2): 517-22.

25 Rebuck AS, Jones NL, Campbell EJ. Ventilatory response to exercise and to $\mathrm{CO}_{2}$ rebreathing in normal subjects. Clinical Science 1972; 43: 861-67.

26 Pyke JE. Australian Health and Fitness Survey 1985. The Australian Council for Health, Physical Education and Recreation Inc, (ACHPER), South Australia, 1987.

27 Leitch AG, Clancy L, Flenley DC. Maximal oxygen uptake, lung volume and ventilatory response to carbon dioxide and hypoxia in a pair of identical twin athletes. Clincial Science 1975; 48: 235-8.

28 Coonan W, Dwyer T. Recommended Guidelines and Protocols for the Establishment of a National Fitness, Health and Physical Performance Survey in Australian Schools. The Australian Council for Health, Physical Education and Recreation Inc (ACHPER), South Australia, 1983.

29 Astrand PO, Rodahl K. Textbook of Work Physiology: Physiological Basis of Exercise 3rd edn. London: McGraw-Hill, 1988; 378.

30 Schaefer KE. Respiratory pattern and respiratory response to carbon dioxide. J Appl Physiol 1958; 13: 1-14. 